JOURNAL

of Health Inequalities

\title{
The health crisis in 2020 - an example from Lithuania
}

\author{
Justina Vaitkevičiūtè \\ The Lithuanian University of Health Sciences
}

ADDRESSE FOR CORRESPONDENCE: Justina Vaitkevičiūtè, Health Research Institute, Lithuanian University of Health

Sciences, Kaunas, Lithuania, e-mail: justina.vaitkeviciute@lsmuni.It

Supplementary materials (slides from the conference) are available in Webbappendix at the Journal's website: https://www.termedia.pl/ Journal/Journal_of_Health_Inequalities-100

Lithuania was no exception and faced the difficulties caused by the COVID-19 pandemic. Various areas have been affected - business, tourism, education, social and cultural life. However, health care and public health have suffered the most. High rates of morbidity, complications, and mortality from COVID-19 have caused significant challenges to the health care system. In total 2266 people died of COVID-19 in Lithuania in 2020. The mortality rate was 81.1 per 100,000 population. In 2020, a total of 114,002 people became ill with COVID-19. The disease accounted for $5 \%$ of all causes of death in 2020 .

However, other prevention and health services have also been affected. With the start of quarantine, access to health care for the population was restricted. The number of services provided to them also decreased, as did the number of diseases diagnosed. Doctors consulted by phone, but some scheduled surgeries, procedures, tests, etc. were postponed. On average, a patient visited a doctor more than 9 times a year for several years, and in 2020, that number dropped to 6.3 times a year. At the same time, the number of adults suffering from certain diseases has decreased. For instance, the number of cases of cardiovascular disease in 2019 was 295.9 per 1,000 population, and in 2020 it decreased to 287.1 per 1,000 population. Decreased morbidity rates may indicate an insufficiently effective diagnosis of diseases.

In Lithuania, standardized mortality has decreased in recent years, but in 2020 it increased. Mortality from diseases of the circulatory system in Lithuania decreased until 2019. Last year mortality from diseases of the circulatory system increased and there were 795.2 cases per 100,000 population.

For many years, the life expectancy at birth in Lithuania has been increasing. However, in 2020, life expectancy was shorter compared to 2019 (76.43 years in 2019 and 75.11 years in 2020). We can argue that the COVID-19 pandemic was one of the main factors that affected the health status of the Lithuanian population in 2020.

The challenges facing the healthcare sector in 2020 will have long-term consequences. Late diagnosis and treatment of diseases will require more difficult treatment and will increase health care expenditures in the future. Although the vaccination of the population helped to control the pandemic, the rising morbidity and hospitalization rates in the autumn of 2021 show that the health situation in Lithuania is still complicated. The government's focus on preparing the health care sector for such unforeseen crises is crucial.

Key words: COVID-19, health crisis, morbidity, mortality.

\section{ACKNOWLEDGEMENT}

The information was prepared using data from theLithuanian Department of Statistics (Statistics Lithuania) and the Institute of Hygiene.

\section{DISCLOSURE}

The author reports no conflict of interest. 